\title{
A new role for the synaptonemal complex in the regulation of meiotic recombination
}

\author{
Nancy M. Hollingsworth \\ Department of Biochemistry and Cell Biology, Stony Brook University, Stony Brook, New York 11794, USA
}

\begin{abstract}
Proper segregation during meiosis requires that homologs be connected by the combination of crossovers and sister chromatid cohesion. To generate crossovers, numerous double-strand breaks (DSBs) are introduced throughout the genome by the conserved Spo11 endonuclease. DSB formation and its repair are then highly regulated to ensure that homologous chromosomes contain at least one crossover and no DSBs remain prior to meiosis I segregation. The synaptonemal complex $(\mathrm{SC})$ is a meiosis-specific structure formed between homologous chromosomes during prophase that promotes DSB formation and biases repair of DSBs to homologs over sister chromatids. Synapsis occurs when a particular recombination pathway is successful in establishing stable interhomolog connections. In this issue of Genes \& Development, Mu and colleagues (pp. 1605-1618) show that SC formation between individual chromosomes provides the feedback to downregulate Spo11 activity, thereby revealing an additional function for the SC.
\end{abstract}

In the 1950s, electron microscopists discovered an evolutionarily conserved, meiosis-specific structure formed between homologous chromosomes, unique to prophase I, called the SC (Fig. 1A). The SC physically connects homologs during prophase I and is removed prior to metaphase I, when homologs are connected instead by the combination of crossovers and sister chromatid cohesion. What is the function of the SC? Decades of research have shown that this elaborate chromosomal structure is critical for the regulation of recombination, the process by which crossovers are generated.

SC formation begins with the condensation of sister chromatids along meiosis-specific protein cores to make axial elements. Axial elements from homologous chromosomes are "zippered" together by the insertion of the central region. (Note that after synapsis, axial elements are called lateral elements [Fig. 1A].) The central region is comprised of (1) transverse filaments located perpendicular to the lateral elements, and (2) the central element,

[Keywords: aneuploidy; double-strand breaks; meiosis; recombination; Spo11; synaptonemal complex; trisomy]

Corresponding author: nancy.hollingsworth@stonybrook.edu

Article is online at http://www.genesdev.org/cgi/doi/10.1101/gad.345488. 120 . which runs parallel to the lateral elements midway through the central region (Page and Hawley 2004).

In many organisms, including budding yeast and mammals, recombination is used to identify which chromosomes are homologs. Recombination is initiated through DSBs introduced by the conserved Spo11 endonuclease (Keeney et al. 2014). DSBs are processed to produce single-stranded, recombinase-bound ends that search for homologous chromosomes (Brown and Bishop 2015). In budding yeast, a subset of these DSBs is processed by the Zip1, Zip2, Zip3, Mer3, Msh4, and Msh5 (ZMM) pathway, which uses a functionally diverse set of proteins, including the transverse filament protein, Zip1, and a SUMO ligase, Zip3, to generate double Holliday junction intermediates (Pyatnitskaya et al. 2019). These intermediates are then specifically resolved into crossovers that are distributed throughout the genome. The ZMM pathway also produces stable interhomolog connections that nucleate polymerization of Zip1 for synapsis (Börner et al. 2004). In this way, synapsis results from the successful creation of interhomolog recombination intermediates destined to become crossovers.

The axial element plays critical roles both in the generation of DSBs and the regulation of their repair. It provides the platform on which proteins required for DSB formation, including Spo11 and Rec114, are assembled (Panizza et al. 2011). Hot spots are regions in the genome preferentially cleaved by Spo11. Hot spots are located on chromatin loops and are brought to the axes where they are cut by Spo11 (Fig. 1A; Keeney et al. 2014). DSBs result in the recruitment of the meiosis-specific kinase Mek1 to axial elements, where it is activated and promotes interhomolog bias, regulates the ZMM pathway, and controls the meiotic recombination checkpoint (Hollingsworth and Gaglione 2019).

What does the central region do? The central region is not required for making crossovers, as crossovers are formed by alternative pathways in $z m m$ mutants. A clue came from the observation that the "homolog engagement" promoted by ZMM genes down-regulates Spo11

(C) 2020 Hollingsworth This article is distributed exclusively by Cold Spring Harbor Laboratory Press for the first six months after the full-issue publication date (see http://genesdev.cshlp.org/site/misc/terms.xhtml). After six months, it is available under a Creative Commons License (Attribution-NonCommercial 4.0 International), as described at http://creativecommons.org/licenses/by-nc/4.0/. 
A

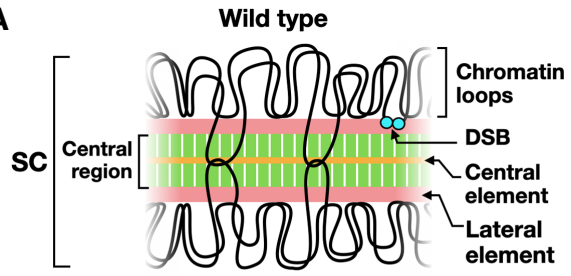

B

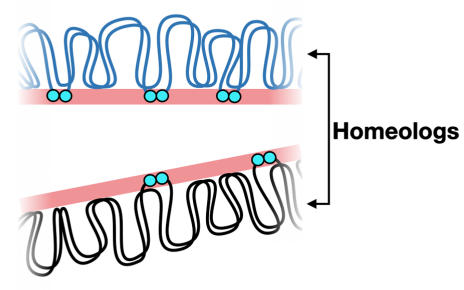

C

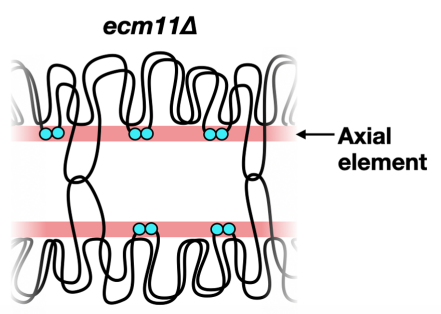

Figure 1. The relationship of DSB formation to synapsis in different situations. $(A)$ The synaptonemal complex. When chromosomes are synapsed, recombination intermediates contain double Holliday junctions (shown by intersecting loops). When cells exit pachynema, the stage of meiotic prophase when chromosomes are fully synapsed, Holliday junctions are resolved to form crossovers and the SC is disassembled. DSB formation is greatly reduced by synapsis but is not completely abolished until cells exit pachynema. (B) Sequence diversity between homeologous chromosomes largely inhibits recombination and synapsis, resulting in persistent DSB formation. $(C)$ In the absence of the central element, the transverse filament is not assembled, resulting in chromosomes that lack the central region. Recombination intermediates containing double Holliday junctions are still formed, but DSB formation is not down-regulated.

activity, suggesting synapsis could be responsible (Thacker et al. 2014). However, due to the pleiotropic nature of $\mathrm{zmm}$ mutants, alternative possibilities could not be ruled out. Using a multipronged approach, $\mathrm{Mu}$ et al. (2020) show that assembly of the central region during synapsis reduces Spo11's ability to make DSBs in a chromosome-autonomous manner.

To test the importance of synapsis in down-regulating Spol1 activity, Mu et al. (2020) monitored DSB formation in diploids containing specific chromosomes that either were unable to synapse because only one homolog was present (monosome) or rarely synapsed because the two homologs contained divergent DNA sequences (homeologs) (Fig. 1B). Because recombination and synapsis occurred normally on the 15 other homolog pairs, these chromosomes acted as internal controls. DSB levels were monitored by Southern blots of whole chromosomes or by quantifying the oligonucleotides that remain cova- lently attached to Spol1 after cleavage. In both cases, DSBs were increased specifically on the monosomic or homeologous chromosomes. This increase was not due to the formation of new hot spots, but due to more breaks occurring at existing hot spots. Deletion of ZIP3, which prevents synapsis between all of the homologs, did not further increase the frequency of DSBs on the homeologs, suggesting it is the SC formation function of ZIP3 that is responsible for lowering the frequency of DSBs.

To determine whether the presence of the central region is required for down-regulation of Spol1 activity, the investigators used mutants in the central element protein-encoding genes, ECM11 and GMC2. These proteins interact with the $\mathrm{N}$ terminus of Zip1 to promote Zip1 polymerization and formation of the central region (Leung et al. 2015). In their absence, the ZMM pathway forms crossovers, but synapsis does not occur (Fig. 1C). Both ecm11 1 and gmc2s exhibited increased amounts of DSBs. In wild-type cells, DSB frequency is inversely correlated with chromosome size. This correlation was lost on all chromosomes in the zip3 $\Delta$ and ecm $11 \Delta$ mutants. In contrast, in wild-type cells, only the monosomic or homeologous chromosomes exhibited an increase in DSBs that was disproportionate to chromosome size. Synapsis is therefore sufficient to down-regulate Spo11 activity on individual chromosomes.

How does synapsis inhibit Spol1 activity? Mu et al. (2020) show that Rec114 (part of a protein complex that recruits Spol1 to the axial element) persists specifically on homeologous chromosomes. This result suggests that the assembly of the central region promotes removal of the DSB machinery from axial elements, thereby decreasing the ability to make DSBs. The function of the central region in turning off DSB formation is likely conserved, as synapsis during meiosis in mice removes axis proteins that promote DSB formation (Wojtasz et al. 2009).

Having unleashed Spol1 to make DSBs, it is imperative that the cell knows when to turn Spoll off. Because SC formation requires the generation of stable interhomolog recombination intermediates, synapsis provides the feedback that DSBs are no longer needed and actively promotes the down-regulation of Spo11. Mu et al. (2020) have made an important contribution to our understanding of the SC by revealing another critical function for this fascinating meiotic structure.

\section{Acknowledgments}

Thanks to Ed Luk for help in making the figure, and to Aaron Neiman, Ed Luk, and members of the Hollingsworth laboratory for providing comments on the manuscript. N.M.H. is supported by National Institutes of Health grant R01 GM050717.

\section{References}

Börner GV, Kleckner N, Hunter N. 2004. Crossover/noncrossover differentiation, synaptonemal complex formation, and regulatory surveillance at the leptotene/zygotene transition of meiosis. Cell 117: 29-45. doi:10.1016/S0092-8674(04)00292-2 
Brown MS, Bishop DK. 2015. DNA strand exchange and RecA homologs in meiosis. Cold Spring Harb Perspect Biol 7: a016659. doi:10.1101/cshperspect.a016659

Hollingsworth NM, Gaglione R. 2019. The meiotic-specific Mek1 kinase in budding yeast regulates interhomolog recombination and coordinates meiotic progression with doublestrand break repair. Curr Genet 65: 631-641. doi:10.1007/ s00294-019-00937-3

Keeney S, Lange J, Mohibullah N. 2014. Self-organization of meiotic recombination initiation: general principles and molecular pathways. Annu Rev Genet 48: 187-214. doi:10.1146/ annurev-genet-120213-092304

Leung WK, Humphryes N, Afshar N, Argunhan B, Terentyev Y, Tsubouchi T, Tsubouchi H. 2015. The synaptonemal complex is assembled by a polySUMOylation-driven feedback mechanism in yeast. I Cell Biol 211: 785-793. doi:10.1083/jcb .201506103

Mu X, Murakami H, Mohibullah N, Keeney S. 2020. Chromosome-autonomous feedback down-regulates meiotic DNA break competence upon synaptonemal complex formation. Genes Dev (this issue). doi:10.1101/gad.342873.120
Page SL, Hawley RS. 2004. The genetics and molecular biology of the synaptonemal complex. Annu Rev Cell Dev Biol 20: 525558. doi:10.1146/annurev.cellbio.19.111301.155141

Panizza S, Mendoza MA, Berlinger M, Huang L, Nicolas A, Shirahige K, Klein F. 2011. Spo11-accessory proteins link double-strand break sites to the chromosome axis in early meiotic recombination. Cell 146: 372-383. doi:10.1016/j.cell .2011 .07 .003

Pyatnitskaya A, Borde V, De Muyt A. 2019. Crossing and zipping: molecular duties of the ZMM proteins in meiosis. Chromosoma 128: 181-198. doi:10.1007/s00412-019-00714-8

Thacker D, Mohibullah N, Zhu X, Keeney S. 2014. Homologue engagement controls meiotic DNA break number and distribution. Nature 510: 241-246. doi:10.1038/nature 13120

Wojtasz L, Daniel K, Roig I, Bolcun-Filas E, Xu H, Boonsanay V, Eckmann CR, Cooke HJ, Jasin M, Keeney S, et al. 2009. Mouse HORMAD1 and HORMAD2, two conserved meiotic chromosomal proteins, are depleted from synapsed chromosome axes with the help of TRIP13 AAA-ATPase. PLoS Genet 5: e1000702. doi:10.1371/journal.pgen.1000702 


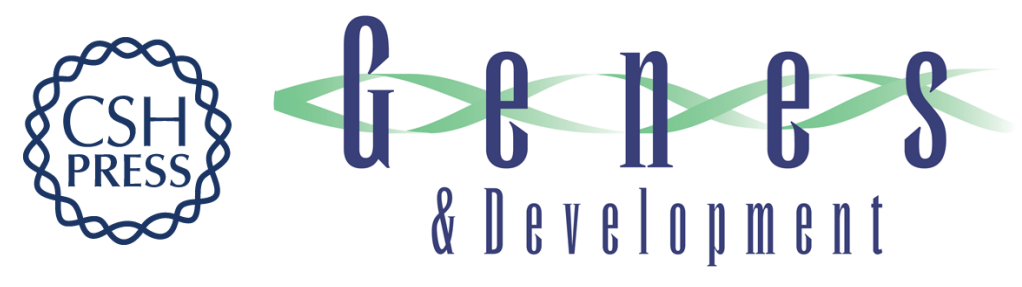

\title{
A new role for the synaptonemal complex in the regulation of meiotic recombination
}

Nancy M. Hollingsworth

Genes Dev. 2020, 34:

Access the most recent version at doi:10.1101/gad.345488.120

\begin{abstract}
Related Content
Chromosome-autonomous feedback down-regulates meiotic DNA break competence upon synaptonemal complex formation

Xiaojing Mu, Hajime Murakami, Neeman Mohibullah, et al.

Genes Dev. December , 2020 34: 1605-1618

References This article cites 11 articles, 3 of which can be accessed free at:

http://genesdev.cshlp.org/content/34/23-24/1562.full.html\#ref-list-1

Articles cited in:

http://genesdev.cshlp.org/content/34/23-24/1562.full.html\#related-urls

Creative This article is distributed exclusively by Cold Spring Harbor Laboratory Press for the first

Commons

License

six months after the full-issue publication date (see

http://genesdev.cshlp.org/site/misc/terms.xhtml). After six months, it is available under a

Creative Commons License (Attribution-NonCommercial 4.0 International), as described at http://creativecommons.org/licenses/by-nc/4.0/.

Email Alerting

Receive free email alerts when new articles cite this article - sign up in the box at the top

Service right corner of the article or click here.
\end{abstract}

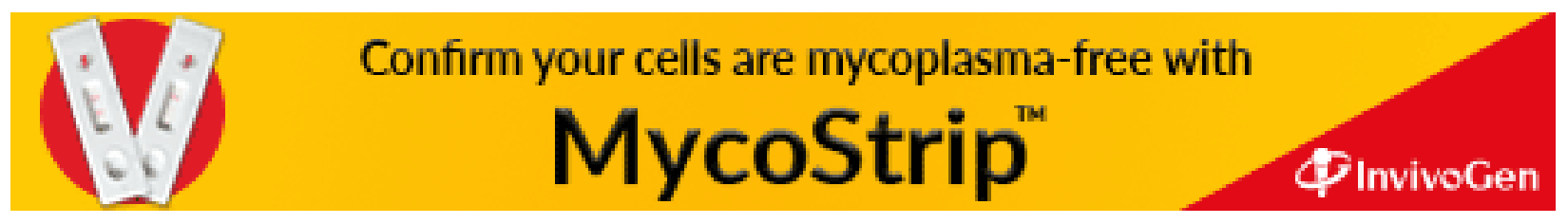

